\title{
The Comprehensive Approach - Doctrinal Overview and Swedish Leadership Implications at the Operative and Tactical Level
}

\author{
Alicia Ohlsson, $M A$ \\ Swedish National Defence College, Department of Security, \\ Strategy and Leadership, Karlstad, Sweden \\ alicia.ohlsson@fhs.se \\ Dr. Claes Wallenius \\ Research psychologist, Swedish National Defence College \\ claes.wallenius@fhs.se

\section{Dr. Gerry Larsson} \\ Swedish National Defence College, Department of Security, \\ Strategy and Leadership, Karlstad, Sweden \\ gerry.larsson@fhs.se
}

This research was financially supported by the Swedish National Defence College. Correspondence concerning this article should be addressed to Alicia Ohlsson, Swedish National Defence College, SE-6518o Karlstad, Sweden.

Email: alicia.ohlsson@fhs.se

\footnotetext{
* Alicia Ohlsson is a researcher at the Swedish National Defence College. She holds a Masters in psychology focused on clinical and counseling for both individuals and families. Her areas of research thus far have been focused on leadership and stress at both the individual and organizational level within military contexts.

** Claes Wallenius has a PhD in psychology and a position as a research psychologist at the Swedish National Defence College. His research interest is leadership, group dynamics, stress management, decision-making and the changing political conditions for the defence sector.

*** Gerry Larsson is a professor of leadership psychology at the Swedish National Defence College and at Hedmark University College, Norway. Dr. Larsson has published extensively in the areas of leadership, stress, personality and organization.
} 


\begin{abstract}
This article is built upon a doctrinal and literature review of comprehensive approach (CA) concepts and the larger international actors that currently use them, such as the UN, EU and NATO. It also focuses on how small actors, such as Sweden, can contribute within this collaborative framework. There is a focus on possible leadership challenges and suggestions of individual characteristics that would be desirable to handle these types of challenges. Examples of leadership challenges from Swedish informants were used to enrich the text from a Swedish perspective.The findings can be summarized with the following:
\end{abstract}

(1) The UN, EU and NATO differ on how far they have developed cA core conceptual documents and to what levels they have implemented the approach within their international missions.

(2) Sweden does not currently have a comprehensive approach of its own but seems to be headed in that direction. Small actors, such as Sweden, can mainly contribute to the larger actors with "plug-in" capabilities.

(3) Possible challenges and competencies were identified and compared to the current leadership model used for the Swedish Armed Forces, Developmental Leadership.

Our analysis indicates that although the current theoretical model of the Swedish Armed Forces holds up well to several cA factors, it could benefit to incorporate new concepts within the model that were identified as specific to a comprehensive approach context.

\title{
Keywords
}

comprehensive approach - challenges - leadership - individual characteristics Swedish Armed Forces

\section{Introduction}

Recently, there has been a focus on major actors involved in international peacekeeping missions to incorporate a variety of a comprehensive approach to their holistic strategy when cooperating with other nations and civil actors in an international setting. It has been stated that up to $50 \%$ 
of peace keeping processes may relapse within a five year period. ${ }^{1}$ In an attempt to improve these meagre results, different strategies and coordinating efforts have been initiated in order to achieve better harmonization and synchronization among coordination efforts of international and local actors. ${ }^{2}$

At the national level, many countries have implemented some type of whole of government approach, including Sweden. We believe that it is interesting to see how a smaller national actor, such as Sweden, can contribute to a larger international arena and how adopting the CA in an international arena would affect leadership at the operational and tactical level. Our aim of this literature and doctrinal review is to see what adopted comprehensive approach organizational concepts already exist in larger organizations such as the European Union, United Nations and North Atlantic Treaty Organization and what affect this may have on Sweden. It is also our aim to see how these combined international efforts may affect leadership at the operational and tactical levels along with what desirable characteristics at the individual level may be optimal to meet these challenges. We believe this is valuable as during the last decade Sweden has become increasingly involved in international peacekeeping and peace-enforcement missions, mainly in cooperation with the UN and EU. This article illuminates this by focusing on military leadership and the compatibility of the current Swedish model of military leadership with demands posed by a comprehensive approach.

This article is divided into five parts. The first is an overview of the doctrines and core concepts that were found which included the comprehensive approach. It attempts to answer the following question: What doctrinal and conceptual basis regarding the comprehensive approach exists within NATO, the EU, the UN and in Sweden? The remaining four parts build on this review of the literature and challenges identified. The second part is devoted to an analysis of leadership challenges that follow from a comprehensive approach along with illustrative examples from Swedish soldiers that were involved in international peace-enforcement missions. Part three identifies desired leadership competencies and skills to meet these challenges. Then, in part four, the desired competencies and skills are related to the current leadership model of the Swedish Armed Forces. The fifth and final part presents a discussion and recommendations for future research.

1 Paul Collier, V.L. Elliot, Håvard Hegre, Anke Hoeffler, Marta Reynal-Querol and Nicholas Sambanis, Breaking the Conflict Trap: Civil Wars and Development Policy (Washington, DC: The World Bank, 2003).

2 Cedric de Coning and Karsten Friis, 'Coherence and Coordination: The Limits of The Comprehensive Approach', Journal of International Peacekeeping, vol. 15, 2011, pp. 243-272. 


\section{Methodology}

\section{Literature Review}

The literature was collected from multiple sources. Specifically, the organizational doctrines and core concept documents were downloaded from the following organizations' websites:

- NATO: http://www.nato.int/cps/en/natolive/index.htm

- EU:http://europa.eu/index_en.htm

- un: http://www.un.org/en/

The literature was collected through the electronic database of the Anna Lind library at the Swedish National Defence College. The material was sorted into different categories for review: doctrines from each organization, articles related to each organization, articles relating to Sweden and other Nordic countries, and articles that overviewed the concept of the comprehensive approach.Regarding leadership, some doctrine and core principle documents were more relevant than others; references to those particular documents are listed within the text.

\section{Swedish Informants}

This article originally extends from a report that was ordered from the Swedish Armed Forces in 2012. We felt that the analysis would be strengthened by adding Swedish officers' personal experiences in an international environment which can be assumed to have been using a form of a comprehensive approach. This would give it a more practical depth from a Swedish perspective.

The data used in this article is a secondary analysis of data which was originally collected for a separate purpose. Altogether there were 15 participants in the initial qualitative study, five of these reported international experiences that could be defined from a comprehensive approach perspective and hence forth were fitting to illustrate the types of challenges that were initially found in the literature review. The experiences selected were those that could be used to highlight the challenges that were described in the literature review.

Informants ranged in military rank from cadet to colonel and their ages spanned from 20 to 60 years. The highest level consisted of Chief-of-staff and leaders within Operating Mentoring Liaison Team (омLT). Most informants described their experiences from operations which were coordinated with larger actors in Afghanistan, and one had experience from a United Nations mission in Sudan. All except for one had previous experience in other international missions such as Gulf of Aden, the Balkans, and Lebanon. 
Within the literature, one repetitive problem defined was the lack of a clear definition of the comprehensive approach. It appears that in general it refers more to a concept of different mixtures of military and civilian collaborative efforts and to solving problems that are both military and civilian in nature. The comprehensive approach is neither a specific method nor a specific strategy to follow when organizing a mission. Most definitions include the idea of harmonization and coordination of international, local, civilian and military actors when crises occur. ${ }^{3}$ Within this area there are several concepts that are more or less synonymous with the comprehensive approach. Examples include Integrated Missions (IM), Civil Military Coordination (CMCO) and coordinated efforts.

The contexts where the comprehensive approach should be applied are often broad and varied in nature. Afghanistan, Kosovo and Iraq are a few examples of the countries that are most frequently discussed in the current literature which have had international missions using a comprehensive approach. With such varied environments, effectively implementing a comprehensive approach poses many challenges.

The concept of a comprehensive approach has been debated and also, to some extent, criticized. Some have noted that it has a reputation as a "catchphrase of little consequence". ${ }^{4}$ Others have highlighted the need for operationalizing the concept and many have questioned its effectiveness. ${ }^{5}$

An issue that needs to be addressed regarding implementation of a comprehensive approach is the consequences and development opportunities for leadership. Leadership, like the comprehensive approach, is a broad concept with a lack of consensus within research on how exactly to define it depending on the circumstance. Our theoretical framework for leadership for this article will be based on an interactive model that is discussed and compared to our literature findings in section four.

3 Cedric De Coning, 'Civil-Military Relations and un Peacekeeping Operations', World Politics Review, vol. 19 May 2010.

4 Philipp Rotman, 'Built on Shaky Ground: The Comprehensive Approach in Practice', Research Paper no. 63, (Rome: Nato Defence College, 2010).

5 Julian Lindley-French, Paul Cornish and Andrew Rathmell, 'Operationalizing the Comprehensive Approach', Programme Paper ISP PP 2010/or (London: Chatman House, 2010).; Peter Viggo Jakobsen, 'Right Strategy, Wrong Place - Why NATo's Comprehensive Approach will fail in Afghanistan', UNISCI Discussion Papers, no. 22. (Madrid: Research Unit on International Security and Cooperation, 2010). 
1.1 Three International Organizations' Perspectives on the

Comprehensive Approach

This section will focus on three of the biggest multi-national organizations, NATO, UN, and the EU, and their progress to obtain a comprehensive approach within their organizational frameworks.

\subsubsection{North Atlantic Treaty Organization}

According to our findings, it appears that NATO has not successfully integrated the comprehensive approach into their doctrines. It is currently focusing on developing the comprehensive approach as an operational concept based on its Effect-Based Approach to Operations (EBAO). Essentially, NATO is a military alliance and therefore can only be deployed as such. ${ }^{6}$ It is not built in a manner to implement a comprehensive approach on its own. Therefore, after the 2008 Bucharest Summit, it was declared that NATO's role within the comprehensive approach is only that of a contributor due to the lack of civilian capabilities within its organization. ${ }^{7}$ However, Coning and Friis state that because NATO is a contributor to efforts led by the $\mathrm{EU}$ and $\mathrm{UN}$ in international affairs, it can be considered to be adopting a comprehensive approach as a form of policy coherence. $^{8}$

\subsubsection{The European Union}

Over the past ten years, the EU has made considerable progress in its efforts to establish a better- functioning comprehensive approach. The European Security Strategy (ESS) was adopted in December 2003 and has been their core doctrine regarding a unified European approach toward security challenges. According to Gross, this document came as a result of the EU's involvement in Iraq. ${ }^{9}$ It was an attempt to create a coherent culture within the EU member states to repair damage done from conflicting views regarding their involvement there. The Ess also discusses the need and challenges for civilian and

6 Kristiina Rintakoski and Mikko Autti, 'Comprehensive Approach: Trends, Challenges and Possibilities for Cooperation in Crisis Prevention and Management', Seminar Publication on Comprehensive Approach, cas Research Team (Helsinki: Crisis Management InitiativeMinistry of Defence, 2008).

7 NATo, Bucharest Summit Declaration (2008), http://www.nato.int/cps/en/natolive/official _texts_8443.htm, accessed 1 October 2012.

8 Coning and Friis, 'Coherence and Coordination: The Limits of the Comprehensive Approach', p. $243^{--272 .}$

9 Eva Gross, 'EU and the Comprehensive Approach', DIIS report 2008:13 (Copenhagen: DIIS Danish Institute for International Studies, Copenhagen, 2008). 
military components to coordinate more effectively. ${ }^{10}$ Since 2003, a Security Strategy Update has been released, which refers to the Lisbon treaty regarding development and changes that the EU should make in developing their comprehensive approach. ${ }^{11}$ Another core document, which includes civil-military components, is the Common Security and Defence Policy (CSDP); this was formerly known as the European Security and Defence Policy (ESDP). This document focuses on its crisis management capabilities and the actors involved in the process.

The EU often uses the acronyms CMco (Civil-Military Coordination) and CIMIC (Civil-Military Cooperation) when discussing civil-military coordination efforts. According to Wendling, CIMIC usually deals with operational and tactical support issues and СMCO is related to the civil and military affairs within the political and strategic level. The use of the terminology within the organization has also led to an actual policy created to reflect these components, the Civilian-Military Coordination Policy. This policy was created to coordinate the elements in field operations and it addresses the need to strengthen the coordination with all actors regarding the planning and followthrough of operations. ${ }^{12}$

\subsubsection{United Nations (UN)}

Out of all three of the organizations, it appears that the Un has the most developed comprehensive approach in combining civil and military components into their missions. They have, however, strategically chosen to call their approach by other names in order to differentiate themselves from other organizations. The UN often uses the name Integrated Approach (IA) when referring to their method of handling complex military-civil tasks. They also have an Integrated Mission (IM), which was first implemented in 2004/2005. The UN's secretary general released a Note of Guidance on Integrated Missions in 2006 stating:

An integrated mission is based on a common strategic plan and a shared understanding of the priorities and types of program interventions that

10 EU, A Secure Europe in a Better World - European Security Strategy (2003), http://www .consilium.europa. eu/uedocs/cmsUpload/78367.pdf, accessed 1 October 2012.

$11 \mathrm{EU}$, Report on the Implementation of the European Security Strategy (2008), http:// www.consilium.europa. eu/ueDocs/cms_Data/docs/pressdata/EN/reports/104630.pdf, accessed 1 October 2012.

12 Cécile Wendling, 'The Comprehensive Approach to Civil-Military Crisis ManagementA Critical Analysis and Perspective', IRSEM report 2010 (Paris: Institut de Recherche Strategique de l'Ecole Militaire, 2010). 
need to be undertaken at various stages of the recovery process. Through this integrated process, the UN system seeks to maximize its contributions towards countries emerging from conflict by engaging its different capabilities in a coherent and mutually supportive manner. ${ }^{13}$

They have also implemented an Integrated Missions Planning Process (IMPP) which is an organized and systematic way to include all of the actors involved during a crisis, including all of the local actors in the host country and those involved at the UN headquarters.

After comparing several organizations, including EU, UN and NATO, Wendling stated that the "UN remains the international organization with the longest experience of the multidimensional approach through its integrated approach". ${ }^{14}$ Overall, this organization has an advanced doctrinal plan to address civilian-military unified endeavors even though it is labeled differently than the other organizations.

\section{$1.2 \quad$ Where Does Sweden Stand?}

Sweden does not currently have a comprehensive approach of its own but has a variation of the whole of government approach. Grönberg states that in March of 2008 the Swedish government presented a national strategy for Swedish participation in international peace-support and security-building operations to the Swedish Parliament. It included Swedish support for combined civil and military actors. Grönberg further elaborates that the combination of these two sides has been challenging for Sweden in the past since civilian and military efforts are often separate. Previously, the Swedish military and civilian agencies have had different mandates and priorities which have resulted in difficulties when working together. The national strategy presented in 2008 recognizes that contributions must include both civil and military capabilities in order to be successful. It is also noted within the national strategy that the Swedish involvement is to support UN and EU peace efforts while also achieving Sweden's overall national objectives. ${ }^{15}$

$13 \mathrm{UN}$, Note of Guidance on Integrated Missions, issued by the Secretary-General on 9 December 2005, paragraph 4. See also the Revised Note of Guidance on Integrated Missions, dated 17 January 2006, and released under a Note from the Secretary-General on 9 February 2006, paragraph 4.

14 Wendling, 'The Comprehensive Approach to Civil-Military Crisis Management- A Critical Analysis and Perspective', p. 5 1.

15 Göran Grönberg, 'A Swedish Approach to Comprehensiveness', in Karsten Friis and Sanaa Rehman, eds., Nordic Approaches to Whole-of-government - in Afghanistan and Beyond (Oslo: Norwegian Institute of International Affairs, 2010), p. 25-29. 
It is our analysis that this recognition appears to support the idea that Sweden is moving towards the ideology of a comprehensive approach in an international arena even though it has not been fully established at this time within its doctrine. According to the Swedish Defence Research Agency, the Swedish approach is a "concerted action" of grouped support and the overall level of ambition is collaborative. The Swedish approach is a variant of a Whole of Government Approach and is not part of an international system at this time. ${ }^{16}$

There is currently not a unified Nordic approach either, although it has been suggested by researchers as a possible beneficial collaboration in the future. Each Nordic country has its own policy and certain countries are more developed than others within the process of implementing a comprehensive approach into their own doctrines. Friis and Rehman reported that Sweden has stated its willingness to use a Whole-of-Government approach when it participates in international crisis management. ${ }^{17}$ They continue to say that the main role that Sweden appears to have when implementing a comprehensive approach at this time is to help by contributing to larger actors that are also using the approach in the international arena. Small actors, such as Sweden, will usually contribute to the larger actors within a mission with "plug-in" capabilities depending on the needs of the mission. "Plug-in" capabilities are specific skills or needs that a country can contribute. Friis and Rehman conclude by saying that the effectiveness of the ability to use a comprehensive approach can be measured in terms of inter-agency coherence in the field with key actors such as the UN, the EU, NATO and other large contributors. ${ }^{18}$

\section{Challenges and Implications for Operational/Tactical Leadership Illustrated from a Swedish Perspective}

Within the comprehensive approach doctrine and literature, many challenges have been brought forth in efforts to find ways to implement the approach in a more effective manner. Several of the challenges that were identified that

16 Henric Roosberg, 'Civil-Militär Samverkan i Koncept och Doktrin - En Jämförande Begreppsutredning av Allomfattande Ansats, coIN, civil-militär samverkan och CıMIC' ['Civil-Military Cooperation in Concept and Doctrine - A Comparative Conceptual Investigation of Comprehensive Approach, coIn, Civil-Military Collaboration and CIMIC], FOI-R- -332- -SE (Stockholm: Swedish Defence Research Agency, 2011).

17 Karsten Friis and Sanaa Rehman, eds., 'Nordic Approaches to Whole-of-Government - in Afghanistan and Beyond', Security in Practice 6, NUPI Report (Oslo: Norwegian Institute of International Affairs, 2010). 
could affect leadership are discussed below, specifically at the tactical and operational level.An example of each type of challenge is illustrated below from a Swedish perspective.

\subsection{Distal Challenges}

\subsubsection{Complexity of the Task}

The task for a comprehensive approach mission/operation is normally complex and possibly one of the more challenging tasks a military leader faces. The end-state of an operation: peace, democracy, and functional societal institutions, are normally a result of a long term, historical process which is hard to accelerate. The perception of injustice in different population groups may be an obstacle, but this is also a process that may need time to evolve. These are examples of structural problems behind the leadership challenges that, in the short run, are hard to affect.

There are more factors that contribute to this complexity, like different and parallel political agendas, as well as cultural differences both within the organization and in relation to the host nation.

Below, a Swedish commander describes the challenges he encountered when working with local defense forces in Afghanistan:

What was really challenging, that was what a person calls the "Local Defense Forces", which were different armed Afghan units in several locations that all had different mandates.

Being able to keep up with the different actors involved in missions and which mandates and rules that were applicable with each unit was challenging to coordinate internal actors according to their different rules/mandates. A wider variety of cultural differences will be addressed more extensively under proximal challenges.

There is also an emotional complexity. The comprehensive approach is normally exercised in a context of conflict, which in itself is emotionally provocative. Research has indicated that many different emotion-coping strategies are often used in order to help individuals handle the emotionally taxing situation. Examples of these are distancing, rationalizing, externalizing, etc. These can be healthy in a short term perspective to handle complex, emotionally challenging situations but can be harmful in a long term perspective. ${ }^{19}$

19 Nilsson, Brandow, Ohlsson, Alvinius and Larsson, 'Military Leadership and Emotion Coping in Acute Situations that Include Moral Dilemmas', ISsL/LC Report Series I:86 
In addition, there may be an emotional aspect related to the use of and the distribution of power. The local population of the host country may be cooperative in varying degrees, some more so than others. This has been the experience from several Swedish operations.An example of this was found from a commander that was involved in a UN mission in Africa:

This is something I had a hard time with in Africa, or it felt like a challenge, not actually solving the tasks given, more of interacting with the local population...At least in Africa, you had this feeling that you were perceived as "Here comes the white man again that is going to try and help us figure out a problem that he himself has created"...

There may also be divergences between the multiple actors involved that may put pressure on leadership. Combined with other environmental stressors, this means that there is a constant demand on military leaders to handle multiple balancing acts.

\subsubsection{Political Understanding/Support}

Some of the problems encountered by these multi-national organizations appear to be that the origin of the comprehensive approach is at the political and strategic level and that there may be a lack of consensus between different members. Coning and Friis note that there is limit of coherence within these larger organizations. Specifically, there is a considerable gap between the policy level and therefore an inability to achieve coherence at the operational level. ${ }^{20}$

At the tactical and operational level, a commander has to accept the results of political processes, even if he or she does not find the outcome optimal from a military point of view. Several Swedish commanders, platoon leaders and soldiers questioned the political support they perceived that they received in international missions, especially concerning morally challenging decisions that often need to be made. Much of the questioning had to do with what they were allowed to do versus what they would like to do in morally taxing situations in an international arena. It is also important that a leader feels he/she has support from the leading group and political level in specific situations that demand it.

(Karlstad: Swedish National Defence College- Department for Security, Strategy and Leadership, 2013).

20 Coning and Friis, 'Coherence and Coordination: The Limits of the Comprehensive Approach', pp. 101-110. 
A commander within an international peacekeeping mission reported:

And with that (mandates), I also experience very strongly that those involved in Swedish political leadership don't care that much about what we do. They want to be involved politically but I sometimes question if they take the moral responsibility for what they let us be involved with and do.

It appears that commanders would benefit from an understanding of the political processes behind the decisions.

\subsubsection{Complex Decision Making}

Decision making on different levels may differ considerably in what kind of leader qualities they demand. On lower levels the decisions may be more short-term and involve fewer alternatives and circumstances to balance. Higher levels within a hierarchal scheme simply involve more complex decisions. It could be argued that the increase in complexity seems to be more exponential than linear. As a commander moves up to the international and intercultural level, there are more circumstances to balance when making decisions. He or she must have the competence to identify these circumstances, judge their importance, search for relevant information and decision support, analyze data and compare alternatives.

There is also a challenge regarding the different rules/mandates from the different countries that are involved within one international organization. In this circumstance described below, Swedish laws sometimes were different than the rules/laws of the organization, which in this circumstance was the United Nations:

All of the Rules of Engagement, well I shouldn't say all, several of them were not really applicable within the legal support we had from here (Sweden) until the government changed the page on its offensive mission rules, this was also the case where you take the initiative to carry out, exercise violence.

This presents a challenge for what is expected from an organizational level (e.g. U.N.) versus what is allowed at a national level.

\subsection{Proximal Challenges \\ 2.2.1 Cultural Competence}

Several types of cultural competencies are important in the implementation of the comprehensive approach. In international operations, leaders first need an 
understanding of the culture of both the host nation and the participating nations. Typically, the countries in which comprehensive-approach missions are conducted have very different cultures, and a leader needs to be aware of the differences as well as having a level of diplomacy on how to handle differences in a respectful way. Even small cultural offences can be disadvantageous when trying to get the local people and the diverse participating actors to work with you on a task, rather than against your efforts.

Because the use of the comprehensive approach involves many different actors and organizations, it also demands a competence for different organizational cultures. This is, however, a complex issue. The organizational culture could often mirror the kind of tasks the organization has, as well as its past history. To add to the complexity, an organization (whether it is military or civilian) does not have one uniform culture, but rather several subcultures within itself.

One of the biggest challenges though, is for both the military and civilian actors that are involved to have a mutual respect for what each has to offer to the comprehensive approach process. It can often be felt within the organizations that either side has a hard time relating to the other's perspective and they can often think that their own side's contribution is worth more than the others. An example of this at the Swedish (operational level) was given by an informant who routinely worked with several civilian actors within a peacekeeping mission in Afghanistan. In this circumstance, the informant was working with the Afghan police and this person reflected on the difference in cultural views they held toward women:

...their view (Afghan) of women were completely outdated, there were several police that were sitting and laughing and having a discussion and then when the interpreter was asked what it was about he said, "they are sitting and talking and comparing who mistreats their wife the most", and then I was like "is that a competition?" and their view of women was totally absurd...

When asked if their conflicting views affected their working relationship, the informant replied:

No, I already knew about it before the mission so it didn't affect me really, it was more like "well, that is their view". Instead you began to look down on them actually, on their closed views and double-morals.

Another example was reported of how unpleasant the civil actors were with the local population, in which they were depending on for information. It was reported: 
When we were out on an operation, it was always with the army and the police, and they could go to a little family to check out the situation (regarding the Taliban) and be pretty rude towards them, although sometimes nice....they would check out the situation and almost demand that they would be served food and then they would sit there and eat all of their food. I would refuse it...

The informant continued with the description, including that the civil actors usually promised to return to pay the family for the food they had eaten; however, they rarely followed through on their promises. For this OMLT soldier, this problem was particularly concerning to him because he felt the civil actors were taking advantage of the families since most of them were very poor and did not have regular access to stores to buy supplies to support their families.

\subsubsection{Time}

Often, in situations when the comprehensive approach will be used, time is of the essence at the beginning of a mission. It is usually critical that an organization or actor be involved as soon as possible when a situation develops to prevent it from worsening. A complication with this press of time is that the decision and planning stages, along with all of the different committees that need to be involved, often take time before the beginning of a mission can commence. According to the United Nation's document, A New Partnership Agenda - Charting a New Horizon for uN Peacekeeping, Integrated Approach and Integrated Missions, a faster deployment to mission sites is critical within the beginning stage of the comprehensive approach. ${ }^{21}$ This needs to be accomplished at the strategic level by establishing a mission headquarters on site so that the prioritization of tasks can be sequenced and begin within a shorter period of time. The document also mentions the need for leaders to be able to do "scenario-planning" in the field in order manage and respond to crisis situations in a timely fashion.

After decisions and plans are made, there is a short turnaround time for units to be put together and then deployed to begin the tactical stage. This can be a challenge for tactical unit leaders because the units that are put together often have no experience working with each other prior to the mission. The leader has to be able to build a relationship and a sense of trust with his/her subordinates along with team building within the group in a very short time period.

21 UN, A New Partnership Agenda: Charting a New Horizon for uN Peacekeeping (2009), http:// www.un.org/en/ peacekeeping/documents/newhorizon.pdf, accessed 1 October 2012. 
A soldier at the tactical level described an educational challenge due to dispatch on short notice:

It was only to get to it and do it (learn on site). There was no alternative. It worked out pretty well for me anyhow and then I helped teach the others that also did not have enough training on it (systems used on site).

\subsubsection{Environment}

As would be expected, being involved in missions within unstable countries poses challenges. It makes the working environment a volatile one that requires a huge amount of flexibility from a leader's perspective. Leaders should be seen as the 'expert' in their own domain because they are the ones that have the most relevant and current knowledge upon which to base decisions.

A description from an informant shows the type of changing, chaotic environment they experienced in Mogadishu and the challenges it presented:

In 2010 in Mogadishu... a lot had happened but it was a full on war zone there and the government forces were almost non-existent that had physical control over parts of the harbor and the presidential palace. In general, the whole city was...lawless and especially under the influence of the Al-Shabab, which was a type of terrorist group connected to Al-Qaida.

This type of example illustrates the type of volatile, risk-filled environment that a mission could take place. This, of course, takes a special type of individual, equipped with many different abilities and skill sets to make decisions in this type of environment and to bear the responsibilities that follow along with it.

\subsubsection{Resources}

Short preparation time also has a direct effect for the resources that can be accessible at the mission site when beginning a mission. The operational level must be able to get orders for what resources are needed and be able to get them to the mission site in a quick and timely manner so that the mission can begin as quickly as possible. This can be a challenge as necessary resources often come later than anticipated. This leaves units and leaders in an awkward position on how to begin their tasks.

Receiving resources in a timely manner is not context-specific to the comprehensive approach as it can happen in other types of missions as well. However, something that can be specifically challenging to the comprehensive approach is the need to share resources with other agencies that are also 
involved in the same task at the mission site. This is the true essence of the comprehensive approach: the ability to work together with different agencies in order to complete a similar goal. This can be a challenge because each agency has its own policies, rules, and regulations that it must follow regarding resources. The delay that can take place for an agency to have approval to share resources with another agency/agent is crucial time that could be spent on the mission itself.

Due to the many unknown factors, such as volatile environment and time constraints, the availability of resources could also be unknown. An informant described that:

Yes, and then of course, you really don't have any idea if there is a motorcycle with a bomb on it, that you really can't know. Or a car with something...

As this informant describes, the environment is often unpredictable and the resources often have to be planned in accordance to an event that has happened.

Another challenge is the resources that are available connected with the resources that are used from the local actors. An example of this was given from an informant in regards to protective gear. The Swedish soldiers had all of the protective gear required to work in a high-risk environment, however, many of them chose not to wear it due to the fact that they worked directly with Afghan soldiers who did not have the gear. The informant described that:

It is also that we work according to how they (Afghans) work. We are away and running through the mountains with the Afghan army that has absolutely nothing (protective gear), they have only their uniform and a weapon and they are fast, ya, then it feels like you can't take everything (protective gear).

This became quite a problem later in the mission because the Swedish soldiers were ordered to wear their protective gear and many decided not to in order to adjust to the warm Afghan heat and to make themselves quicker in comparison to the Afghan soldiers they were working with. This was reported to be especially a problem among the younger, less experienced soldiers.

\subsubsection{Conflicts}

Due to the many factors involved in these types of missions, such as multiple actors, ambiguous laws/mandates, cultural considerations, etc. the risk for 
conflicts are heightened considerably. Leaders working in this type of environment should be mentally prepared for probable conflicts and have the ability to handle them in a diplomatic way which is focused on conflict resolution in order to achieve the higher goal of the mission as well as hold the integrity of the other parties. A few examples of types of conflicts international peacekeeping missions are described below:

I was Chief of Staff to eleven officers which were all the same level and rank that I was...There were eleven nationalities, from Russia, Nigeria, Egypt, Rwanda, Norway, England, India and Pakistan. It was this type of glorious mix of nationalities that despite everything worked pretty well together but after they left the organization and went back home then they continued to have conflicts with each other (nations), for example Pakistan and India, those types of tensions. So that was a part of it, to handle those types of ingrained, existing conflicts that were based on which nationalities that were put together in this type of time restricted work environment.

The informant continued by explaining that cultural differences and the combination of different nationalities often created disagreements when there was a need to have unanimous decisions made. There were many differences of opinions about conflict resolution, such as:

In many countries there was a culture of...if people didn't agree, if you take away the problem then the problem is solved. Maybe compromising and finding a middle ground isn't something that works all over the world. That was the first time that I reflected on that. If we're going to achieve any real changes then it's going to take time, an unbelievable amount of time.

When asked how they finally ended up working successfully in a group when they differed so much in opinion, it was answered:

Sometimes you just had to be at peace to say that we are currently not in agreement and then every time you meet it has to be handled with a long term plan instead of a short fix and I think that can definitely be a challenge for Swedish soldiers that are in an international mission. To be away during a time restricted period, you are usually away for 6 months so you want to make your absence from home feel worthwhile, that you have actually achieved something, that you have contributed to 
something. But when you are in that context then you realize, damn, what do I think I am going to accomplish in this 6 months? Probably very, very little. And that can actually be a very tough thought, to give up 6 months and endanger yourself, and to what benefit? Yes, in a very long perspective then there is naturally a little accomplishment achieved but when you are actually there, that accomplishment feels unbelievably small.

One of the problems reported is that these types of disagreements tend to create split views within the organization. It was reported that:

There were split views within our organization. All of us eleven represented UN and the international community and I felt that it was very important that we, we shouldn't sell a "cracked picture" to those we were trying to help fulfill the peace-agreement with. So instead of all trying to agree on all decisions, I decided to split all of the responsibilities up. So, every individual had their clear and specific responsibility area so that on paper we could be united as a UN organization on our decisions and so that we didn't stomp on each other's areas of responsibilities and that minimized those types of conflicts within our organization.

Desired Competencies/Skills and Behaviors for Operational and Tactical Leadership

\subsection{Desirable Leadership Competencies/Skills}

Before looking at specific competencies and skills, the difference between the terms skill and competence should be clarified for the purpose of this article. There are several different definitions for both words but most include the common components that a skill encompasses the ability to do something well; or an expertise. While most definitions of a competence include the core concepts of a person's combination of knowledge, applied skills and behavior related to the competence. Some even include the person's attitude as well. Therefore, a skill should be seen as a subset of being competent in something. To illustrate, social competence can be regarded as a broad concept that includes skills such as giving and receiving feedback constructively and being able to adapt words and body language to different cultures and peoples.

Within the comprehensive approach doctrine and literature there were several skills and/or competencies that were identified as important for implementing the approach within peacekeeping operations. Those skills/competencies were 
interpreted for what would be specifically important for a leader role when implementing the comprehensive approach. They were chosen based on their high frequency of occurrence within several documents. Some of the factors identified are general skills that would be important for other types of leaders in missions that are not related to the comprehensive approach while others are more specific to this context.

\subsubsection{General Skills/Competencies \\ 3.1.1.1 Communication Skills}

Communication skills often include a person's ability to express ideas to others through written, oral and non-verbal ways. Therefore, the effectiveness of a person's ability to express those ideas depends on how well they are at communicating. "Leaders should be effective communicators, both locally and globally. Effective communication of the mission's role and functions to local actors is essential" (United Nations document: A New Partnership AgendaCharting a New Horizon for un Peacekeeping). ${ }^{22}$ Specific to the comprehensive approach, this document emphasizes the importance of good communication skills that a leader should have within Integrated Approach and Integrated Missions. It should be a leader's focus with all of the actors involved within a mission, such as subordinates, the leader's superiors, other leaders, and civilian and actors.

Specific to communication, an important task that leaders should be involved in for the comprehensive approach is involvement in internal/external meetings for planning and receiving of information. This helps coordination and collaboration efforts with the other actors involved. Everyone has the opportunity to work towards a shared goal and it gives a shared situational awareness within the mission. The EU emphasizes the importance of leaders specifically being involved in consultative meetings with other international organizations in the field that are involved in crisis resolution. ${ }^{23}$ This also helps with improved communication between the actors.

Another important form of communication is interaction with the media. Wong, Bliese and McGurk noted that, previously, interaction with the media was a restricted, bureaucratic activity for higher officials within confined settings. With the current trends of increasing real-time reporting and advances of technology, public-relations training is now being added to all

\footnotetext{
22 Un, A New Partnership Agenda-Charting a New Horizon for UN Peacekeeping, accessed 1 October 2012.

23 EU, Civil-Military Co-ordination ( .eu/doc/srv?l=EN\&f=ST\%2014457\%202003\%20INIT, accessed 1 October 2012.
} 
levels of leadership education. ${ }^{24}$ With its growing accessibility, the media can be present for many different critical and daily activities at all levels; leaders should be prepared and skilled in handling the task of dealing with the media. The United Nations emphasizes the importance of clear communication with regards to the media and the need for a well-designed and smooth communication strategy to increase confidence in the peace process and to build trust among parties in the conflict. ${ }^{25}$

\subsubsection{Social Skills}

Current research often links leaders' social skills and ways of interacting with people as a defining concept of being a successful leader. Yukl emphasizes the importance of the need for leaders to be skilled with dealing with people as well as with current issues. ${ }^{26}$ An important aspect of effective social skills is the ability for a leader to be able to change their technical language depending on who he/she is speaking with so that the ideas communicated are easily understood by the recipient. An example of this would be to use terminology that civilians understand rather than using military terminology when having meetings that include civilian participants.

Another social aspect specific to the comprehensive approach that should be considered is the leader's ability to accept and give value to other contributors, including all actors within a mission. This means that he/she openly tries to include other actors within coordination efforts. The leader should be aware of the value that other actors have to offer and, within efforts to coordinate all actors, give them credit for their ideas, a chance to be heard and have an openness to implement ideas decided upon together. This skill is specifically important due to the challenges that the military and civilian/local actors have felt when trying to coordinate together.

\subsubsection{Stress Tolerance Skills}

Due to the volatile environment and the demand for a leader to be able to handle complex decision making on short notice, a leader should have well developed stress tolerance skills. In general, this type of person should have a

\footnotetext{
24 Leonard Wong, Paul Bliese and Dennis McGurk, 'Military Leadership: A Context Specific Review', Leadership Quarterly, vol. 14, 2003, pp. 657-692.

25 UN, Peacekeeping Operations: Principals and Guidelines (2008). The document is also known as the Capstone Doctrine, http://www.peacekeepingbestpractices.unlb.org/Pbps/ Library/Capstone_Doctrine_ENG.pdf. , accessed 1 October 2012.

26 Gary Yukl, Ledarskap i Organisationer [Leadership in Organisations] (Harlow: Prentice Hall, 2012).
} 
naturally high stress threshold to begin with and also have skills to handle stressful environments. This of course, is a general skill since many types of missions also include this need.

\subsubsection{Specific Skills/Competencies}

There are also several skills/competencies identified that are also general skills for leaders but have more importance when implementing the comprehensive approach. These types are listed below.

\subsubsection{Conflict Management Skills}

This is particularly important because of the many different actors involved in the implementation of the comprehensive approach. As we have discussed earlier, there are many different cultures involved in these types of missions (local cultures, inter-agency cultures and intra-agency cultures) therefore, this is an environment naturally conducive to conflict. This is a skill that can be learned and improved.

According to United Nations Peacekeeping Operations Principles and Guidelines (AKA Capstone Doctrine), conflict management and leadership are very important skills for a start-up of a mission since most of the international staff have not worked together previously. ${ }^{27}$ Pertaining to leadership, the document adds that strong leadership is especially important during the start-up phase when new procedures are being established. Confusion at this stage can be problematic because missions usually develop quickly directly after initial start-up. The start-up and ending of a mission are critical times of change, in which roles are re-defined and many parties are involved, which can also lead to a higher risk of conflicts. These types of events should be anticipated and dealt with immediately so that it does not hinder the mission's goals.

\subsubsection{Cultural Competence}

Cultural competence refers to a person's ability to interact effectively with people from different cultures. ${ }^{28}$ Due to the multiple nations involved, which include differences in cultures, religions, languages, etc., cultural competence is a very valuable asset for a leader to have. They will not only use it for their

27 UN, United Nations Peacekeeping Operations: Principals and Guidelines (2008), accessed 1 October 2012.

28 Mercedes Martin and Billy Vaughn, 'Cultural Competence: The Nuts \& Bolts of Diversity \& Inclusion', in Billy Vaughn (ed). Strategic Diversity \& Inclusion Management Magazine (San Francisco: Diversity Training University International Publications Division, 2007) pp. $31-38$. 
own tasks but it will be of value to help educate and advise their subordinates, who are often in contact with the local people within the mission areas.

The UN discusses the "social impact" of the military on the local country in their Capstone Doctrine. ${ }^{29}$ This specifies that leaders should be aware of their unit's impact on the host country. For example, the mixing of genders in societies that upholds strong traditional gender roles (e.g. limiting the mixing and socializing between genders and employing women) along with other activities that may be unacceptable, such as gambling and drinking, may cause friction within the host country. Leaders must be aware of the social and cultural norms within the host countries and be respectful of their views since these can work against their agenda of working together towards a similar goal within a mission.

\subsubsection{Emotion Management Skills}

This concept is interpreted as an important skill for leaders given the volatile and stressful environment they often work in. This is not a new concept within academia but it has gained popularity within the last 10 years in connection to leadership. Emotion management is defined as "the management of feeling to create a publically observable facial and bodily display". ${ }^{30}$ The ability of leaders to control their own feelings in order to match the feelings that are appropriate for the situation is a skill that is especially important when dealing with tasks in emotionally taxing environments. Emotional management has been shown to be a central characteristic of effective leaders, both with regulation of their own emotions and the regulation of others. ${ }^{31}$

Within the realm of emotion management, an idea that has gained interest within the psychology and management fields is the concept of emotion regulation (ER). Gross describes $\mathrm{E} \mathrm{R}$ as a "process by which we influence which emotions we have, when we have them, and how we experience and express them". ${ }^{32}$ He describes emotion regulation as a conscious process that can involve increasing, decreasing or maintaining emotions.

Regulation of one's own emotions is referred to as intrinsic regulation. This is more of a general concept that would be important for most actors within an

29 UN, United Nations Peacekeeping Operations (2008), accessed 1 October 2012.

30 Arlie Russel Hochschild, The Managed Heart: Commercialization of Human Feeling (Berkeley, CA: University of California Press, 1983).

31 Amir Erez, Vilmos F. Misangyi, Diane E. Johnson, Marcie A. LePine and Kent C. Halverson, 'Stirring the Hearts of Followers: Charismatic Leadership as the Transferal of Affect', Journal of Applied Psychology, vol. 93, 2009, pp. 602-615.

32 James J. Gross, 'Emotion regulation: Affective, Cognitive, and Social Consequences', Psychophysiology, vol. 39, 2002, pp. 281-291. 
international mission. Extrinsic regulation refers to the skill of helping others regulate their feelings. This concept has led to emotion regulation strategies, which are skills that can be learned in order to regulate one's own emotions and/ or help others with the regulation of their emotions in a given situation. These strategies would be particularly important for leaders to use when encountering emotionally charged situations, such as a crisis, to help themselves or others to decrease their own emotions in order to keep calm to fulfil a task.

Blascovich and Hartel discuss the importance of how emotions are communicated from person to person within different cultural settings and how misunderstandings can easily happen based on the cultural interpretation of the event (often resulting from non-verbal behavior). ${ }^{33}$ They indicate that as the military increasingly trains and conducts missions abroad within multicultural environments, knowledge of the cultural difference (specifically emotional aspects) will be important to mission success.

\subsection{Desirable Leadership Behaviors}

Within the comprehensive approach doctrine and literature there were also several behaviors or ways of being that were described as being beneficial in implementing the comprehensive approach. All of these aspects can be seen as both general leadership abilities and as abilities specific to the comprehensive approach.

\subsubsection{General Leadership Behaviors \\ 3.2.2 Highly Adaptive/Flexible}

Due to the complex and constantly changing comprehensive approach environment, a focus on increased flexibility for leaders at the operational level is necessary so that they have the ability to adapt and adjust accordingly. Both tactical and operational leaders need to be flexible to plans changing at short notice and be able to change plans themselves when they find the current plan is not working. The E U's Report on the Implementation of the European Security Strategy discussed the importance of increased flexibility in order to be successful when implementing the comprehensive approach. ${ }^{34}$ They correlate the need for higher flexibility with the heightened complexity of the task. The document is also specific with the need to have troops/leaders who have the flexibility for short- notice deployment.

33 James J. Blascovich and Christine R. Hartel (eds), Human Behavior in Military Contexts (Washington, DC: The National Academies Press, 2008).

$34 \mathrm{EU}$, Report on the Implementation of the European Security Strategy, accessed 1 October 2012. 


\subsubsection{Inspire/Motivate Others}

This is valuable so that subordinates feel motivated to complete necessary tasks within the mission. More specifically, it is important that the leader is open with information that is necessary for subordinates to have an idea of the motivation behind their own tasks. This creates meaning to their work rather than a checklist of tasks to fulfill without the understanding of why.

\subsubsection{Trust}

Leaders should have trust in the people that they are working with. It is counter-productive in a changing environment to try to be in charge of every aspect within a given mission. Just as a leader wants trust from their subordinates in order to lead them, it is equally important that they also trust their subordinates to follow through with the tasks they have been given. This helps create a culture of trust within the unit and makes it possible for more to be accomplished in a short amount of time. With time being such a critical issue in the comprehensive approach, trust is imperative.

\subsubsection{Cooperation/Coordination}

Due to the complexities of the tasks involved in these types of missions, it is important for leaders to have accurate situational awareness and to draw on the expertise of others to face complexities. The EU states that "in integrated missions, leaders should have the capacity to assess progress, draw on specialized expertise to identify critical gaps, and to work with a range of partners to meet peace-building needs". 35

In order to be more adequately prepared, leaders should receive education and training that is context-specific for the types of challenges that they are likely to face in the field, including working with other actors. It is stated in the UN Capstone Doctrine that this is vital for the preparation of leaders. ${ }^{36}$ Training exercises should include civil expertise so that coordination feels natural in the field. More training, including training with international actors, should be encouraged. This should help with the coordination and cooperation endeavors that seem to be problematic at the field level.

Prior to a new mission, contact time for leaders should be provided so that they have a chance to get to know others who will be involved in the mission. Establishing these relationships encourages an easier ability for cooperation later. The UN's Capstone Doctrinerefers specifically to this in regards to leadership, emphasizing the importance of leaders being able "participate in

\footnotetext{
35 Un, A New Partnership Agenda- Charting a New Horizon for UN Peacekeeping (2009), accessed 1 October 2010, p. 22.

36 Un, Peacekeeping Operations, Principals and Guidelines (2008), accessed 1 October 2012.
} 
the mission planning, briefings on the situation and to meet and work with their colleagues in mission leadership". ${ }^{37}$

\subsubsection{Feedback}

The ability to give feedback is paired closely with a leader's communication ability. It is very important that a leader at this level gives feedback to those he/she is working with. They need to know at an evaluative level how they are doing individually and as a team in order to feel fulfilled and to develop themselves further.

\subsubsection{Role Model}

A leader should behave in a way that portrays the way he/she wants others also to behave. A great deal of leadership research stresses the importance of a leader acting as a role model to his/her subordinates, especially in the popular leadership theories such as transformational leadership. This is, of course, a balancing act of responsibilities as well. Everyone involved within a mission is ultimately responsible for their own behavior so the organizational rules and regulations should be the defining norm for how an individual should act. However, a leader also has a very good opportunity to show the appropriate way to be, defined by the organization.

\section{$4 \quad$ Implications for Swedish Military Leadership at the Operational and Tactical Levels}

Based on the existing doctrinal and conceptual texts on the comprehensive approach, we have tried to deduce challenges implied from a leadership perspective, and, following from this, to identify leadership skills/competences and behaviors that are desirable to meet these challenges. We will now turn to an analysis of what these desirable leadership skills/competencies and behaviors mean for Swedish military leadership. In order to maximize the generalizability of our line of reasoning, we will use a theoretical model of leadership as a road map in this analysis.

\subsection{Identified Factors Compared to a Theoretic Model}

Since 2003, the Swedish Armed Forces has used "Developmental leadership" as its official leadership model. ${ }^{38}$ Recently, two further developments of this

38 Gerry Larsson, Leif Carlstedt, Jens Andersson, Lars Andersson, Erna Danielsson, Ann Johansson, Eva Johansson, Per-Olof Michel and Ingemar Robertson, 'A Comprehensive 
model have been made. First, the contextual part was elaborated, allowing for more situation-specific applications of the model. ${ }^{39}$ Second, aspects from the authentic leadership model, ${ }^{40}$ and from the indirect leadership model, ${ }^{41}$ were integrated with the developmental leadership model. ${ }^{42} \mathrm{~A}$ simplified version of this integrated model was presented by Larsson et al. ${ }^{43}$ and this version will serve as the basis of the present text. The model is shown in Figure 1.

The leadership model implies that a number of individual and contextual characteristics interact and shape a military commander's appraisal or sensemaking of a given situation. This meaning, which applies to what is taking place, in turn generates a number of leadership behaviors, which, to a greater or lesser degree, affect the outcome. Below, a summary of how well the current model upholds to the individual behaviors and competencies that were identified in the doctrines and literature will be summarized.

\subsection{Summary of Leadership Implications}

The present analysis can be summarized as follows. First, all aspects of the theoretical leadership model have been interpreted as being also relevant in a comprehensive approach context. Second, some additional aspects, not mentioned in the existing model, were identified (see Table 1). Additional attention to the aspects summarized in Table 1 is highly recommended as an addendum to the present praxis.

System for Leader Evaluation and Development', The Leadership \& Organization Development Journal, vol. 24, 2003, pp. 16-25.

39 Gerry Larsson and Peder Hyllengren, 'Contextual Influences on Leadership: Theoretical Modelling and Empirical Tests', International Journal of Organizational Analysis, vol. 21, 2013, pp. 19-37.

40 See e.g. William L. Gardner, Bruce J. Avolio, Fred Luthans, Douglas R. May, Fred Walumbwa, 'Can You See the Real Me? A Self-Based Model of Authentic Leader and Follower Development', The Leadership Quarterly, vol. 16, 2005, pp. 343-372.

41 Gerry Larsson, Misa Sjöberg, Aida Vrbanjac and Torsten Björkman, 'Indirect Leadership in a Military Context: A Qualitative Study on How to Do It', The Leadership \& Organization Development Journal, vol. 26, 2007, pp. 215-227; Gerry Larsson, Misa Sjöberg, Sofia Nilsson, Aida Alvinius and Bjørn Bakken, 'Indirect Leadership: A Quantitative Test of a Qualitatively Developed Model', The Leadership \& Organizational Development Journal, vol. 28, 2007, pp. $771-778$.

42 Gerry Larsson and Jarle Eid, 'An Idea Paper on Leadership Theory Integration', Management Research Review, vol. 35, 2012, pp. 177-191.

43 Gerry Larsson, Peder Hyllengren, Misa Sjöberg and Claes Wallenius, 'The Role of the Commander in Future Missions', IsSL/LC Report Series I:72 (Karlstad: Swedish National Defence College, Department of Security, Strategy and Leadership, 2011). 


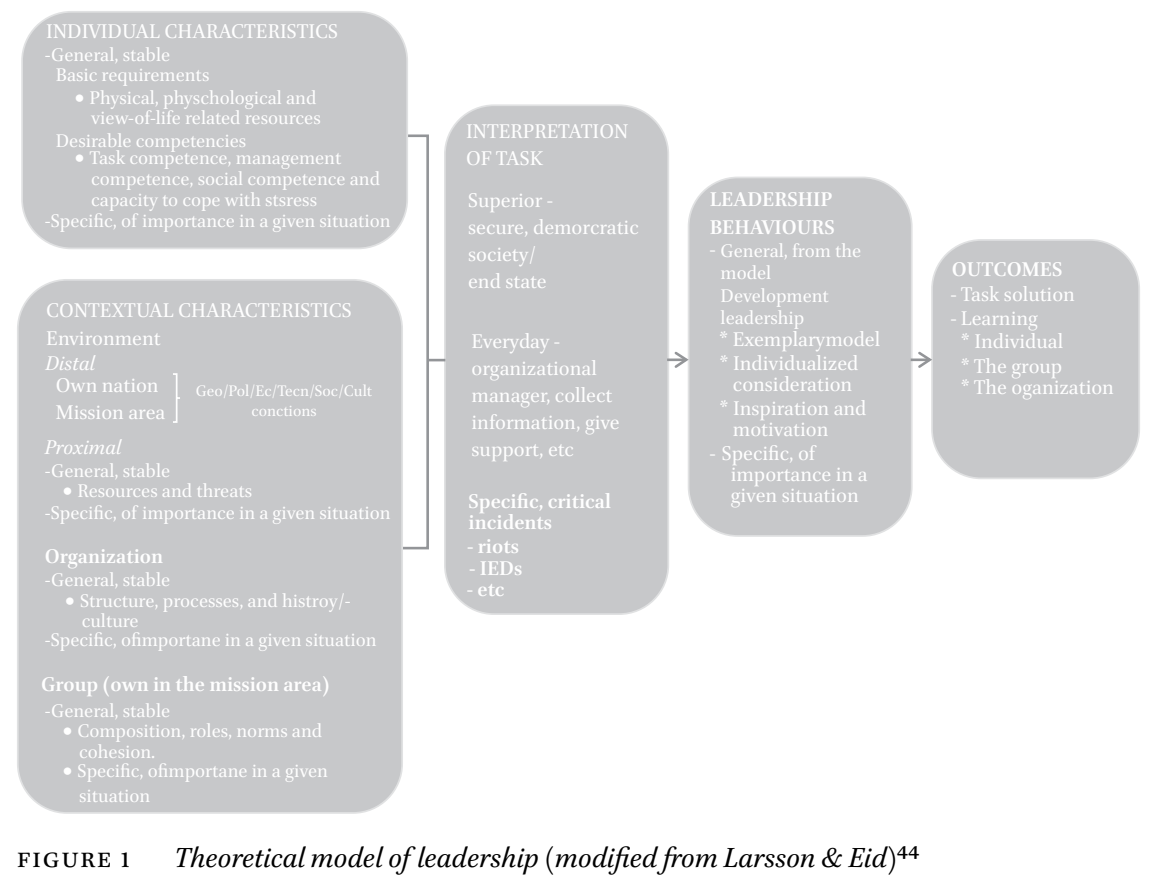

TABLE 1 Comprehensive approach-specific aspects not mentioned in the existing leadership model of the swedish armed forces.

Desirable leader competencies/skills

Selection and education

Conflict management

Cultural competence

Emotion management

Contextual characteristics

Highly complex task

Need for political understanding

Development of relevant and effective

Need for cultural understanding management routines

Lack of time and resources

Highly complex decision making

44 Modified from Gerry Larsson and Jarle Eid (2012). 
TABLE 1 Comprehensive approach-specific aspects not mentioned in the existing leadership model of the swedish armed forces. (cont.)

Theoretical concepts

Practical consequences

Interpretation of task

Selection and education

Inter-individual variation due to

ambiguity of environment and task

Leadership behaviors

Selection and education

Being highly flexible/adaptive

\section{5}

\section{Discussion}

From our literature review it appears that, the UN, EU and NATO, differ on how far they have developed relevant doctrines including a comprehensive approach for international missions. The UN seems to have the most developed approach, despite using different terminology. The routine collaboration with civilian actors within the agency seems to be the defining variable in the development of each agencie's comprehensive approach. Therefore since NATO has no civilian components, it is limited in its ability to have a comprehensive approach of its own but can, however, collaborate with others using the approach.

Pertaining specifically to Sweden, the country has a whole of government approach to handle crisis situations but does not have a comprehensive approach in an international setting. Small actors like Sweden can mainly contribute to the larger actors within a mission with "plug-in" capabilities depending on the needs of the mission.

Our analysis has indicated that the comprehensive approach context can be assumed to put an increased emphasis on the following leadership challenges: highly complex military tasks, a need for political and cultural understanding, a frequent lack of time and resources, and, following from this, highly complex decision making.After comparing the identified challenges to the present leadership model of the Swedish Armed Forces, Developmental leadership, it appears to hold up well against the new challenges.

However, it needs to be complemented with the following competencies/ skills: conflict management, cultural competence, emotion management and 
an increased attention on flexibility/adaptability. The practical consequences following from this can be divided in two broad areas. The first is individualrelated and calls for improved officer selection and education. The second is organization-related and implies a need to develop comprehensive approachrelevant and effective management routines.

Because the present study was literature-based, there is a strong need for empirical studies in military contexts to have any substantial findings. Our review and analysis should be only seen as interesting possibilities for future research opportunities within the comprehensive approach context and the broad span of perspectives it actually hits upon. As this concept gains popularity and focus, it is important to see the different areas impacted. 